\title{
New Hydrophobic Organic Coating based Triboelectric nanogenerator for Efficient and Stable Hydropower Harvesting
}

Bingqiao Wang, ${ }^{a, b}$ Yang $W u^{b, c}$, Ying Liu ${ }^{a, *}$, Youbin Zheng ${ }^{b, c}$, Yupeng Liu ${ }^{b, c}$,

Chenguang Xu $u^{a, b}$, Xiang Kong ${ }^{a, b}$,Yange Feng ${ }^{b, c}$, Xiaolong Zhang ${ }^{b, d}$, Daoai Wang ${ }^{b, c, *}$

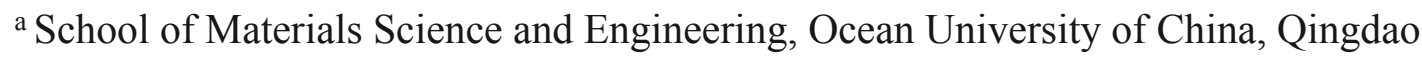

266100, China

b State Key Laboratory of Solid Lubrication, Lanzhou Institute of Chemical Physics,

Chinese Academy of Sciences, Lanzhou 730000, China

${ }^{\mathrm{c}}$ Qingdao Center of Resource Chemistry and New Materials, Qingdao 266100, China

${ }^{\mathrm{d}}$ Hubei Key Laboratory of Hydroelectric Machinery Design \& Maintenance, China

Three Gorges University, Yichang 443002, People’s Republic of China

*Corresponding Author. E-mail: wangda@licp.cas.cn; liuyingwda@ouc.edu.cn 


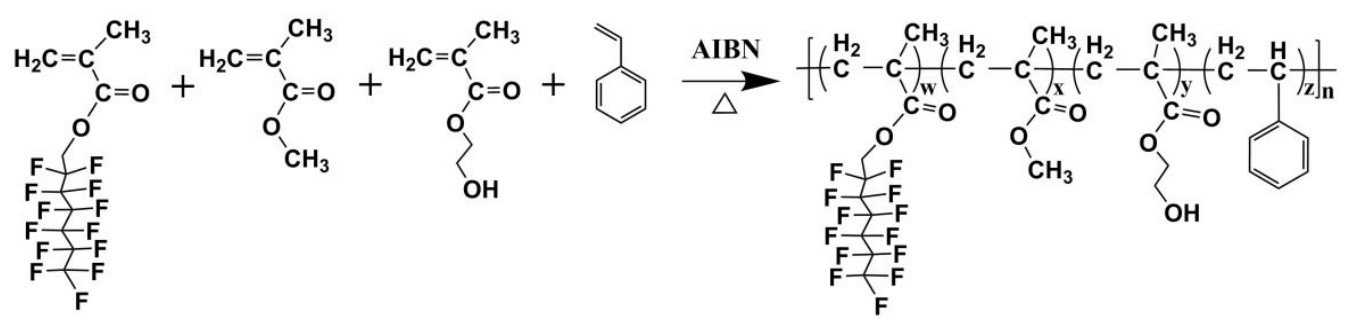

Figure S1. Synthesis pathway of the fluorine modified acrylate resin.
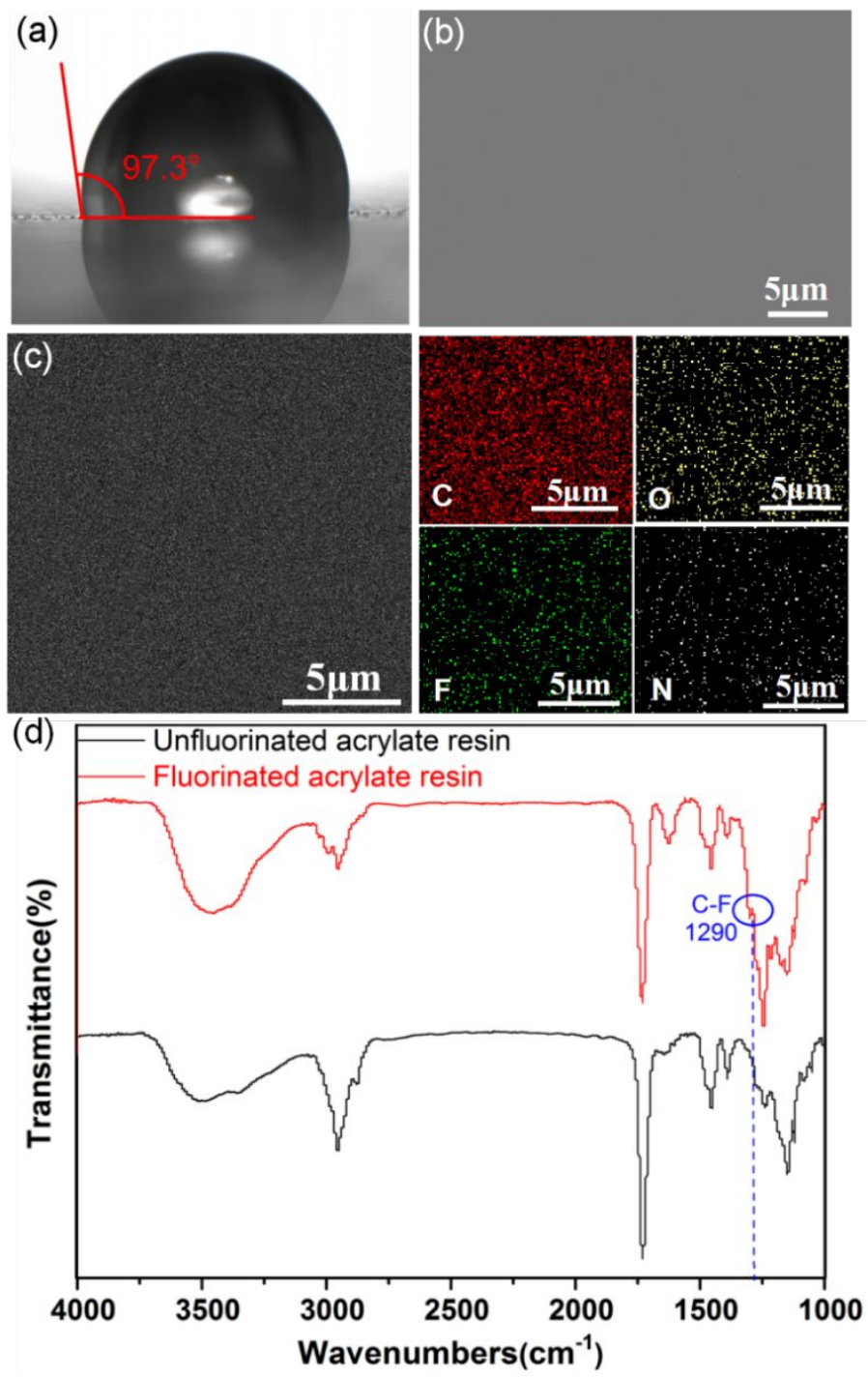

Figure S2. Characterization of hydrophobic coating. (a) Static contact angle of water on coating. (b) SEM image of fluorine modified acrylate resin coating. (c) Element composition analysis of hydrophobic coating. (d) FTIR spectrum of the fluorine modified acrylate resin and non-fluorine modified acrylate resin. 


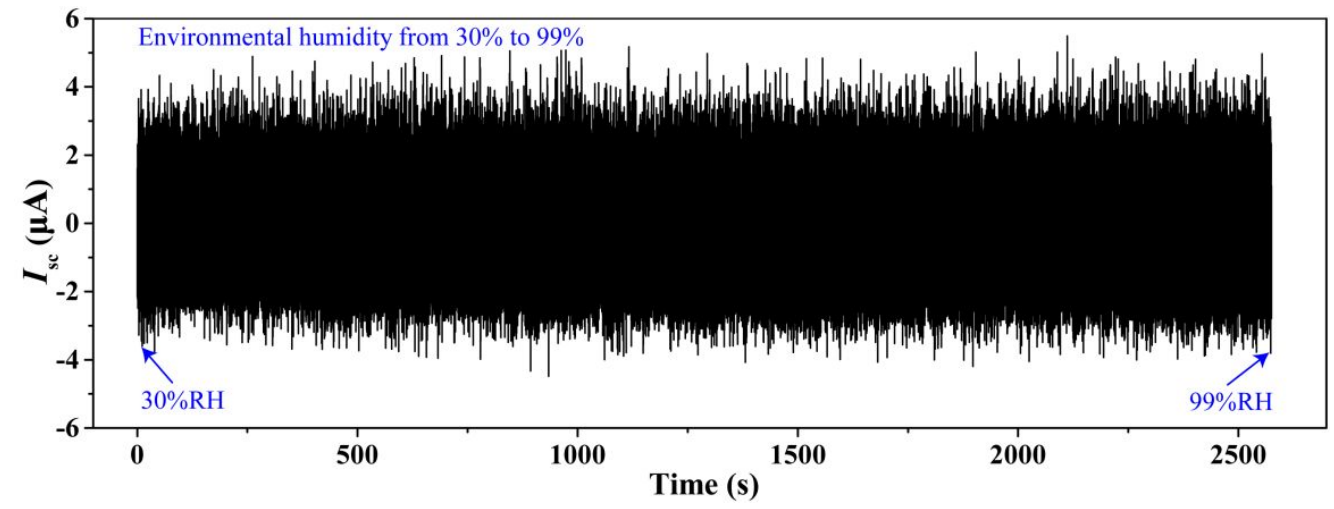

Figure S3. Triboelectric output of OC-TENG in different humidity environments from $30 \%$ to $99 \%$ RH.

(a)

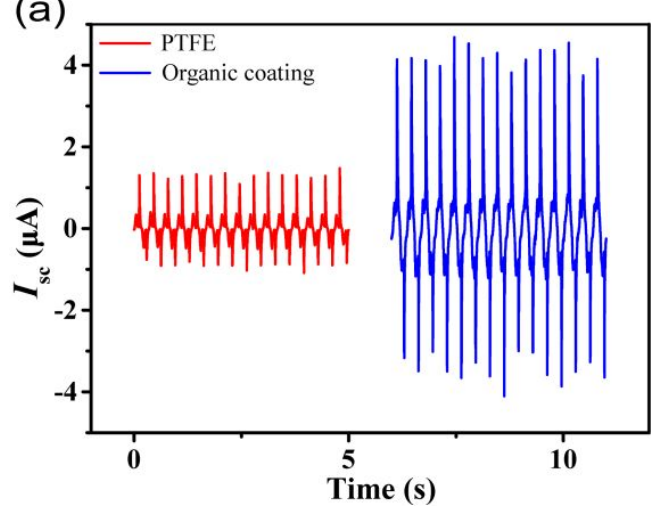

(b)

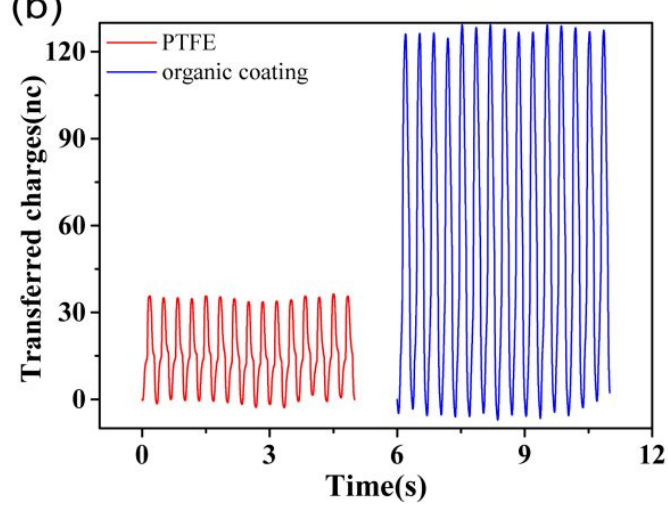

Figure S4. Comparison of (a) short-circuit current $\left(I_{s c}\right)$ performance and (b) Transferred charges of TENG between PTFE and organic coating as friction layer material.

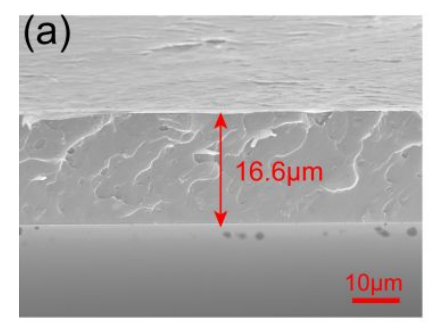

(b)

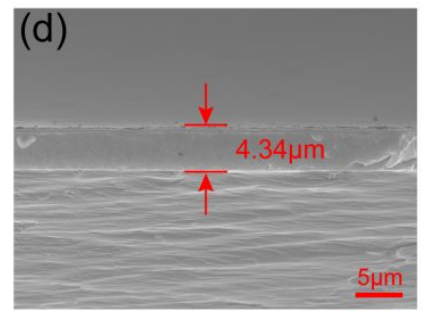

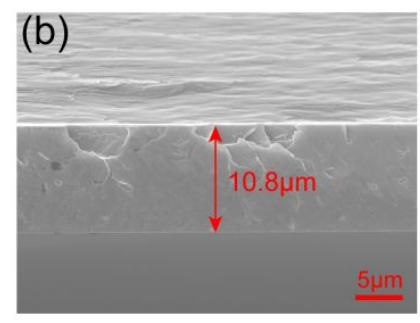
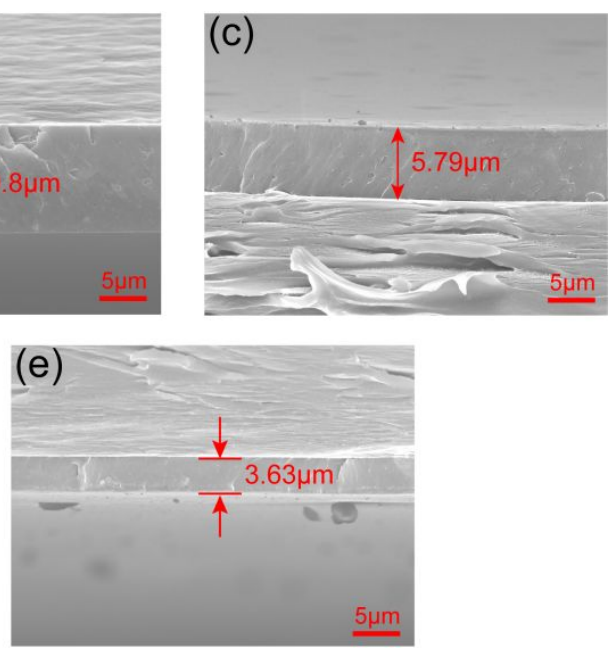

Figure S5. SEM images of coating thickness at different spin speeds. (a) $1000 \mathrm{rpm}$, (b) $2000 \mathrm{rpm}$, (c) $3000 \mathrm{rpm}$, (d) $4000 \mathrm{rpm}$, (e) $5000 \mathrm{rpm}$. 
(a)

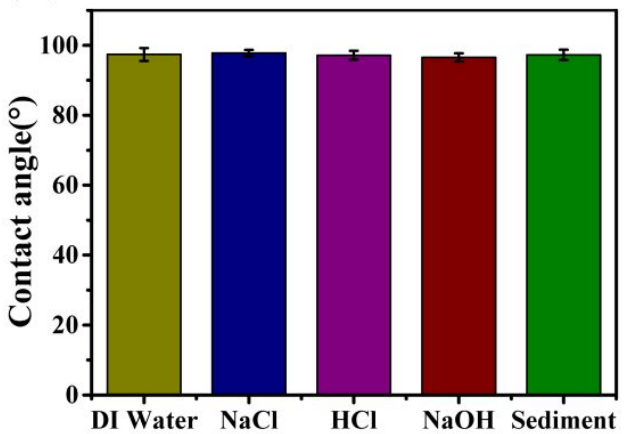

(b)

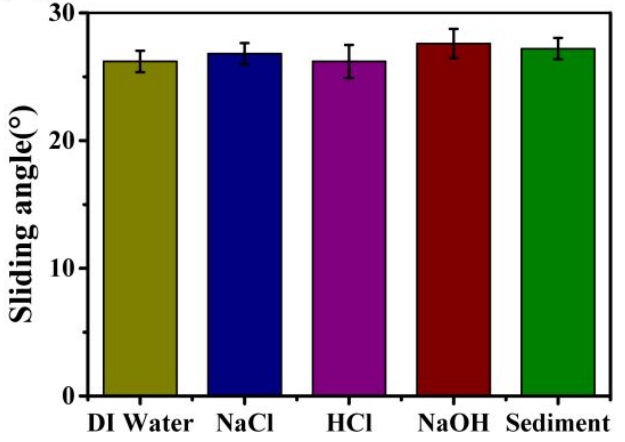

Figure S6. (a) Contact angle and (b) sliding angle of different liquids on the surface of the coating.

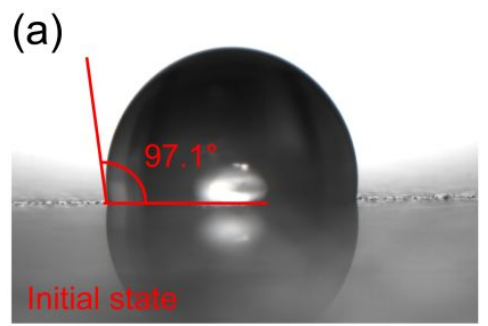

(c)

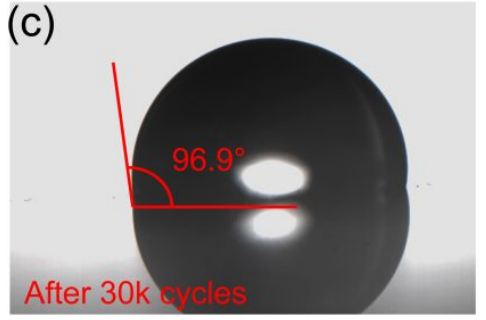

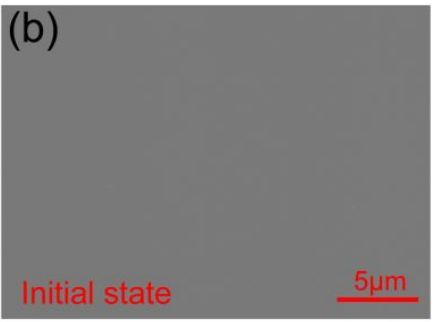

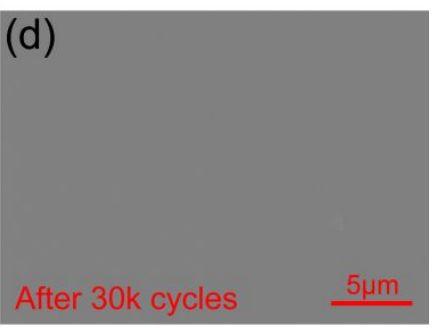

Figure S7. The state changes of SEM image and contact angle before (a, b) and after (c, d) the stability test.

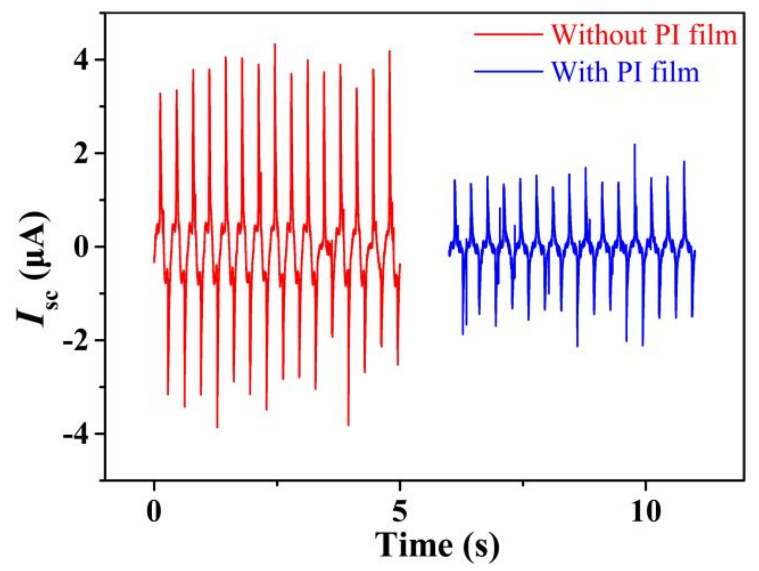

Figure S8. Short circuit current of OC-TENG with and without PI film in the middle. 


\begin{tabular}{|c|c|c|}
\hline & Element Atom (\%) & Element Wt. (\%) \\
\hline $\mathrm{C}$ & 41.6 & 48.6 \\
\hline $\mathrm{N}$ & 17.0 & 17.0 \\
\hline $\mathrm{O}$ & 27.1 & 23.8 \\
\hline $\mathrm{F}$ & 14.3 & 10.5 \\
\hline
\end{tabular}

Table S1. Element Atom (\%) and Element Wt. (\%) in organic coating on ITO surface.

Video $\mathbf{S 1}$ shows that the ship covered by OC-TENG illuminates the LED under the influence of water waves. 